\title{
BILATERAL SUBDURAL HEMATOMA AFTER VENTRICULOPERITONEAL SHUNT SURGERY
}

\author{
Ulas Yuksel*, Ibrahim Akkurt**, Mustafa Ogden***, Bulent Bakar***, Semih Keskil**** \\ * Yildirim Beyazit University Yenimahalle Training and Research Hospital, Department of Neurosurgery, Ankara, Turkey \\ ** Yozgat State Hospital, Department of Neurosurgery, Yozgat, Turkey \\ *** Kirikkale University, Faculty of Medicine, Department of Neurosurgery, Kirikkale, Turkey \\ $\star * * *$ Yuksek Ihtisas University, Faculty of Medicine, Ankara, Turkey
}

\begin{abstract}
Background: Bilateral subdural hematoma (SDH) following ventriculoperitoneal (V/P) shunt application was discussed in present case.

Case Report: 8-year-old girl was operated due to thoracolumbar meningomyelocele immediately after birth. V/ P shunt was inserted in right posterior parietal region due to hydrocephalus when she was 3 month-old. At age of 3 years, V/P shunt dysfunction was considered, and second V/P shunt was inserted in left posterior parietal region. One year after, patient was reevaluated, and CT images showed bilateral subacute SDH. Hematoma evacuation was not considered, but right ventricular catheter was ligated. At four years follow-up, no additional neurological impairment was observed in patient and CT scan revealed that SDHs were retracted greatly.
\end{abstract}

Concusion: It should be kept in mind that SDH could develop after V/P shunt surgery. Additionally, it could be said that one of most important factor in determination of treatment of this complication was primarily neurological examination findings of patient.

Key words: bilateral subdural hematoma; hydrocephalus; ventriculoperitoneal shunt

\section{Introduction}

Although ventriculoperitoneal (V/P) shunt application still is the most commonly used treatment modality in hydrocephalus treatment, various complications arising from this treatment method have been identified in literature. It could come out of the body from anus, vagina, urethra, umblicus or scrotum; and migth cause to intestinal obstruction, pseudocysts formation, intraabdominally $(1,2)$. It also has been reported that it may lead to various problems such as infection (eg meningitis, cerebritis, peritonitis), excessive drainage of the cerebrospinal fluid (CSF) and rarely subdural hematoma (SDH) (3-6). It has been said in the literature that these complications may be more frequent, especially during infancy (1).

In this case report, a child patient with bilateral subdural hematoma following a second shunt application was discussed.

\section{Case Report}

Eight-year-old girl was diagnosed with thoracolumbar myelomeningocele at the time of birth at the external center and she underwent corrective surgery within 48 hours of birth. 3 months later, patient was examined at our clinic and complete power loss in the left leg, complete loss of power in the distal leg muscle group in the right leg, pes equina varus deformity in bilateral foots, congenital hip dysplasia were detected at her examination. Her head circumference was $50 \mathrm{~cm}(99 \%$ area in the percentile curve) and it was determined that it was enlarged in the patient's daily repetitive measurements. Computed tomography (CT) images showed hydrocephalus and V/P shunt was inserted in the right posterior parietal region (Figure $1 \mathrm{~A}$ ). When the patient reached the age of 3 years, she was reevaluated with a tendency to drowsiness, restlessness, fatigue, subfebrile fever and eating difficulties. It was learned from her family that she did not experience any major or minor trauma history. There was no additional neurological deficit added to the previous findings of 
the patient on her nerulogical examination and the second V/P shunt was inserted in the left posterior parietal region, considering that the V/P shunt did not work adequately on the brain $C T$ images. Rightpositioned old V/ P shunt was left in place, considering the risk of bleeding (Figure 1B). Control brain CT and abdominal $\mathrm{X}$-ray showed that cranial and abdominal parts of both V/P shunts were at the desired location. One year after the last operation, the patient was brought back because of being drowsiness. Brain CT images showed a "slit" ventricle with bilateral subacute $\mathrm{SDH}$ (Figure 2). Since there was no additional neurological loss to the previous findings, surgical treatment for subdural hematoma of the patient was not considered and conservative follow-up was decided. But the right-sided V/ $\mathrm{P}$ shunt catheter was ligated surgically to stop CSF drainage, permanently. Patient was discharged without any additional neurological deficits and drowsiness. At four years follow-up, no additional neurological impairment was observed in neurological examination of the patient and her brain $\mathrm{CT}$ scan revealed that subdural hematomas were retracted greatly (Figure 3 ).

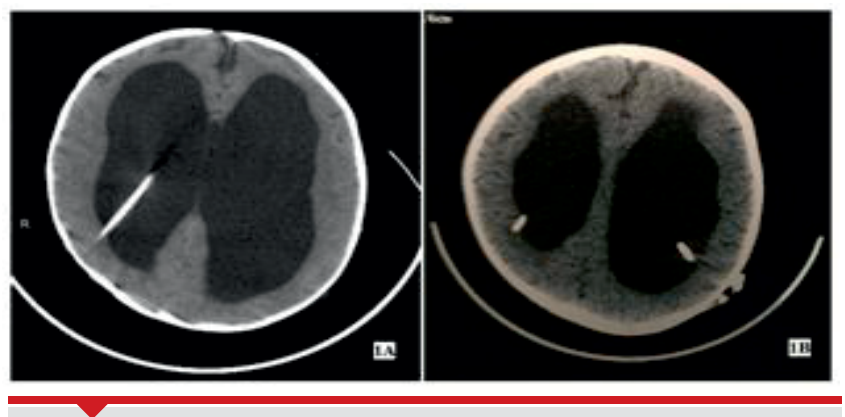

FIGURE 1. Brain CT images show first V/ $P$ catheter inserted in the right posterior parietal region for the patient's hydrocephalus (1A) and the second V/ P catheter inserted in the left posterior parietal region (1B).

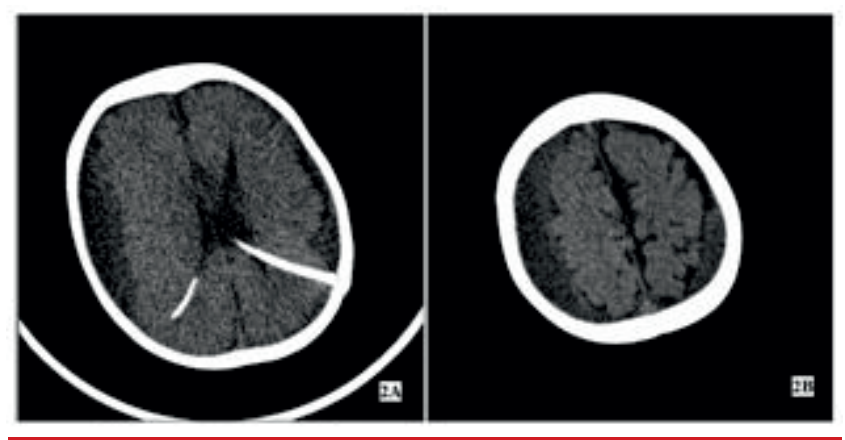

FIGURE 2. Brain $C T$ images of the patient complaining of drowsiness reveal the "slit" ventricles $(2 \mathrm{~A})$ and bilateral subdural subdural hematoma (2B)

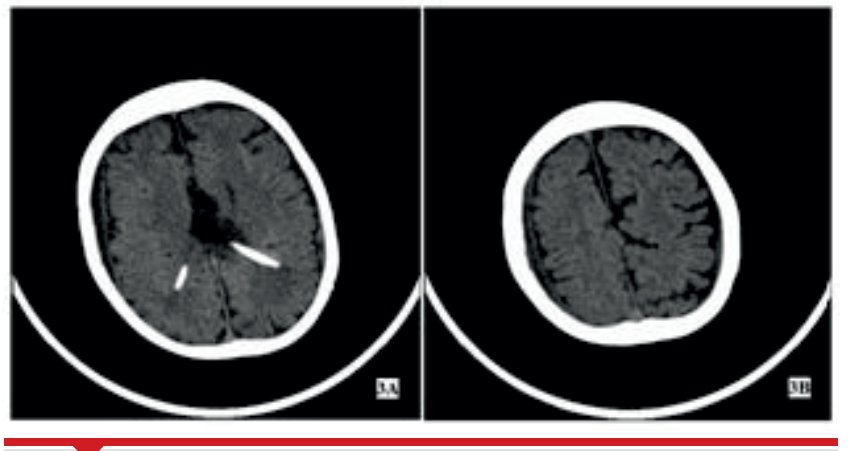

FIGURE 3. After four years of follow-up, brain CT images reveal the greatly retraction of the subdural hematomas

\section{Discussion}

Unilateral or bilateral subdural hematoma related to the $\mathrm{V} / \mathrm{P}$ shunt is rarely reported in literature and some of the V/P shunt patients with this complication do not develop any symptoms and some of them may have chronic headache, hemiparesis, mental retardation, epileptic seizures (7). It is known that over drainage of CSF in patients with hydrocephalus decreases the intracranial volume and causes to detach the brain from the skull. During this detachment, the bridging veins opening to the dural sinuses sometimes tear, and blood leaking from these vessels may accumulate at subdural space $(8,9)$. It was thought that bilateral subdural hematoma developed in present case was not related the trauma. In fact, images of the "slit" ventricule detected in radiological imaging studies suggested that the $\mathrm{V} / \mathrm{P}$ shunts present in the patient overdrainaged the CSF bilaterally. Moreover, it was thought with these images that excessive CSF drainage significantly reduced the intracranial pressure, forced brain tissue to detach from the skull, and caused to rupture the bridging veins bilaterally in our patient.

In literature, it has been suggested that the examination findings of the patient are a very important factor while the decision of the surgical treatment of the subdural hematoma is made. It has been emphasized that conservative treatment may be sufficient in patients without significant neurological impairment (10). Indeed, in our case, surgical intervention of the subdural hematoma was not considered due to the absence of any additional neurological deficit and the absence of any significant effect on the vital function of the patient. On the other hand, the first attached V/P shunt catheter on the right side was ligated surgically to prevent from the excessive CSF drainage. The long-term follow-up of the patient showed a marked decrease in subdural hematoma thickness and content 


\section{Conclusion}

In conclusion, it should be kept in mind that SDH could develop after the V/P shunt surgery. Additionally, it could be said that one of the most important factor in determination of the treatment of this complication was primarily neurological examination findings of the patient.

\section{References}

1. McGirt MJ, Leveque JC, Wellons JC 3rd, Villavicencio AT, Hopkins JS, Fuchs HE, George TM. Cerebrospinal fluid shunt survival and etiology of failures: a seven-year institutional experience. Pediatr Neurosurg. 2002; 36: 248-55.

2. Potineni LB, Hartin CW Jr, Gemme S, Caty MG, Bass KD. Laparoscopic assessment of a migrated ventriculoperitoneal shunt into an inguinal hernia. J Laparoendosc Adv Surg Tech A. 2012; 22: 301-3.

3. Fukuhara T, Vorster SJ, Luciano MG. Critical shunt-induced subdural hematoma treated with combined pressure-programmable valve implantation and endoscopic third ventriculostomy. Pediatr Neurosurg. 2000; 33: 37-42.

4. Hayes J, Roguski M, Riesenburger RI. Rapid resolution of an acute subdural hematoma by increasing the shunt valve pressure in a 63year-old man with normal-pressure hydrocephalus with a ventriculoperitoneal shunt: a case report and literature review. J Med Case Rep. 2012; 6: 393.

5. Stein SC, Guo W. Have we made progress in preventing shunt failure? A critical analysis. J Neurosurg Pediatr. 2008; 1:40-7.

6. Taha MM. Armored brain in patients with hydrocephalus after shunt surgery: review of the literatures. Turk Neurosurg. 2012; 22: 407-10.

7. Castellani RJ, Mojica-Sanchez G, Schwartzbauer G, Hersh DS. Symptomatic Acute-on-Chronic Subdural Hematoma: A Clinicopathological Study. Am J Forensic Med Pathol. 2017; 38: 12630.

8. Louzada PR, Requejo PR, Barroso MV, Vaitsman RP, Machado AL, Paiva MS, Salame JM. Bilateral extradural haematoma after acute ventricular over-drainage. Brain Inj. 2012; 26: 95-100.

9. Mortazavi MM, Denning M, Yalcin B, Shoja MM, Loukas M, Tubbs RS. The intracranial bridging veins: a comprehensive review of their history, anatomy, histology, pathology, and neurosurgical implications. Childs Nerv Syst. 2013; 29: 1073-8.

10. Ludwig B, Nix W, Lanksch W. Computed tomography of the "armored brain". Neuroradiology. 1983; 25: 39-43. 